\title{
Estilos Motivacionais de Professores: Preferência por Controle ou por Autonomia
}

Teacher's Motivational Style:

Preference For Control Or Autonomy

Estilos Motivacionales De Profesores: Preferencia Por Control O Por Autonomía

Amélia Carolina Terra Alves Machado, Sueli Édi Rufini Aline Guilherme Maciel \& José Aloyseo Bzuneck

Universidade Estadual de Londrina
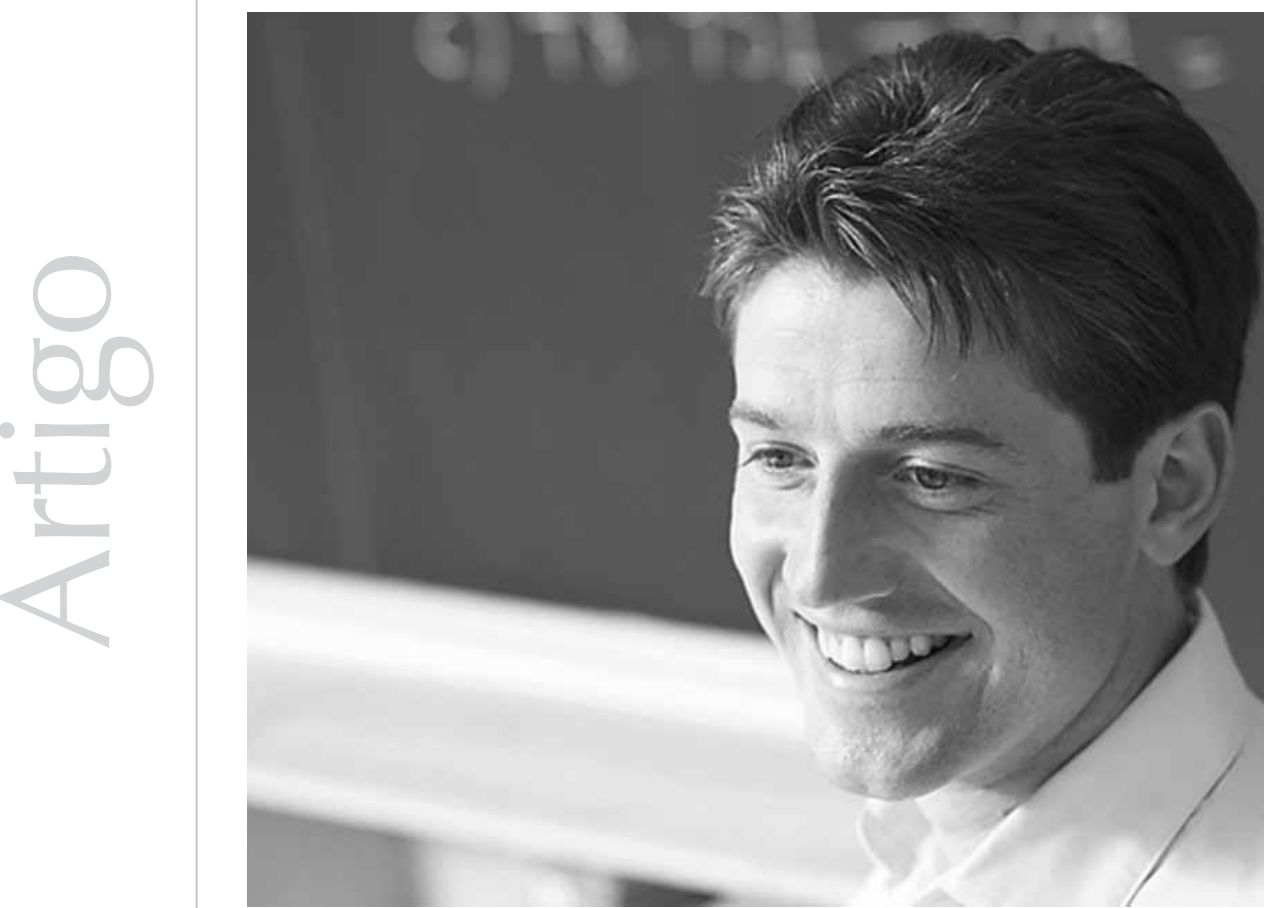
Resumo: A motivação é fundamental para o envolvimento dos estudantes na escola. Para a teoria da autodeterminação, o estilo motivacional do professor, que pode controlar ou promover a autonomia, contribui para fomentar a ocorrência de tipos qualitativamente diferenciados de motivação. Neste estudo, de natureza exploratória, foram analisadas as interações entre dois professores e seus alunos. A amostra foi composta de acordo com o desempenho de 39 professores na avaliação do estilo motivacional, mediante a aplicação de um instrumento de autorrelato, problemas na escola. Desse total, dois professores, um com estilo motivacional promotor de autonomia e outro com uma orientação para o controle, tiveram suas aulas observadas em sete sessões, com o objetivo de levantar dados para a elaboração de um protocolo que continha categorias de interações. Foram então realizadas outras sete sessões de observação. Os resultados indicaram que, apesar de terem sido encontradas diferenças entre os desempenhos na avaliação do estilo motivacional, os professores interagiram com seus alunos de modo preferencialmente controlador. No entanto, o professor que promovia a autonomia interagiu de modo menos controlador no gerenciamento do tempo destinado para a realização das atividades em classe quando comparado ao professor controlador, além de oferecer feedback informativo. As implicações educacionais dos resultados são analisadas.

Palavras-chave: Motivação intrínseca. Motivação extrínseca. Atitudes do professor. Interação professoraluno. Ensino fundamental.

Abstract: Motivation is essential for the students' involvement at school. For the self-determination theory, the
teacher's motivational style, either controller or promoter of autonomy, contributes to foster the occurrence
of qualitatively differentiated types of motivation. In this study of exploratory nature the interactions among
two teachers and their students were observed. The sample was composed according to the score of 39
teachers in the motivational style assessment, by means of the application of a self-report instrument, named
problems at school. Out of this total, two teachers, one with an autonomy promoting motivational style
and the other one, a control-oriented one, had their classes observed along seven sessions, with the aim of
collecting data for the elaboration of a protocol containing interaction categories. Seven other observation
sessions were then carried out. The results have indicated that, despite findings of differences between
the motivational style assessment performances, the teachers preferably interacted with their students in a
controlling manner. However, the autonomy promoter teacher interacted less controllably than the controlling
teacher, as regards the management of time reserved for the accomplishment of class activities, as well as
offering informative feedback. The educational implications of the results are also discussed. Keywords: Intrinsic motivation. Extrinsic motivation. Teacher attitudes. Teacher student interaction. Elementary school.

Resumen: La motivación es fundamental para que los estudiantes se involucren en la escuela. Para la Teoría de la Autodeterminación, el estilo motivacional del profesor, controlador o promotor de autonomía, contribuye para fomentar la ocurrencia de tipos cualitativamente diferenciados de motivación. En este estudio, de naturaleza exploratoria, fueron analizadas las interacciones entre dos profesores y sus alumnos. La muestra fue compuesta de acuerdo con el desempeño de 39 profesores en la evaluación del estilo motivacional, mediante la aplicación de un instrumento de auto-relato, Problemas en la Escuela. De este total, dos profesores, uno con estilo motivacional promotor de autonomía y otro con una orientación para el control, tuvieron sus aulas observadas en siete sesiones, con el objetivo de recolectar datos para la elaboración de un protocolo conteniendo categorías de interacciones. Fueron entonces realizadas otras siete sesiones de observación. Los resultados indicaron que, a pesar de haber sido encontradas diferencias entre los desempeños en la evaluación del estilo motivacional, los profesores interactuaron con sus alumnos de modo preferencialmente controlador. No obstante, el profesor promotor de autonomía interactuó de modo menos controlador en el gerenciamiento del tiempo destinado para la realización de las actividades en clase, comparado al profesor controlador, además de ofrecer feedback informativo. Las implicaciones educacionales de los resultados son analizadas.

Palabras clave: Motivación Intrínseca. Motivación Extrínseca. Actitudes del profesor. Interacción profesorestudiante. Enseñanza Fundamental.

A motivação é um construto hipotético, elaborado com o intuito de explicar, compreender e prever os comportamentos, e refere-se às necessidades e metas pessoais internamente organizadas na estrutura da personalidade (Mayer, Faber, \& Xu, 2007;
Boruchovitch, 2008). No contexto escolar, a motivação relaciona-se de modo positivo com aprendizagem, desempenho, criatividade, persistência e bem-estar, entre outros resultados favoráveis (Bzuneck, 2009). 


\section{Segundo Reeve e Jang (2006), no ambiente de sala de aula, a motivação dos estudantes para a aprendizagem é reflexo de processos intra e interpessoais.}

A teoria da autodeterminação, originalmente proposta por Edward Deci e Richard Ryan (1985), é um referencial que, nas últimas três décadas, tem orientado relevante produção de conhecimento na área da motivação humana. A teoria propõe que toda pessoa possui tendências naturais para o crescimento e necessidades psicológicas que fornecem a base para a motivação autônoma e o desenvolvimento psicológico saudável. Entretanto, para que tais propensões se desenvolvam, são necessárias interações sociais que fortaleçam nos indivíduos sentimentos de competência, autonomia e pertencimento. Em outras palavras, afirma-se que é parte da natureza adaptativa do organismo humano se envolver em atividades interessantes, exercitar capacidades, estabelecer relações com grupos sociais e integrar experiências intrapsíquicas e interpessoais (Deci \& Ryan, 2000, 2004; Reeve, Deci, \& Ryan, 2004; Vansteenkiste, Smeets, Soenens, Lens, Matos, \& Deci, 2010).

Segundo Reeve e Jang (2006), no ambiente de sala de aula, a motivação dos estudantes para a aprendizagem é reflexo de processos intra e interpessoais. Os primeiros referem-se a orientações e crenças internas como, por exemplo, interesses e metas de realização; os últimos resultam das interações sociais, entre as quais se destacam aquelas vinculadas ao professor. Nessa circunstância, os estudantes algumas vezes rejeitam chances para o crescimento, não são automotivados e agem de modo aparentemente irresponsável. Procurando compreender esse paradoxo, a tendência natural para o crescimento e a recusa de oportunidades para seu desenvolvimento, as pesquisas sob o foco da teoria da autodeterminação têm buscado investigar as influências socioculturais a fim de identificar aquelas condições que apoiam ou prejudicam os recursos motivacionais internos dos estudantes (Assor, Kaplan, \& Roth, 2002; Deci, Schwartz, Sheinman, \& Ryan, 1981; Black \& Deci, 2000; Reeve, Jang, Carrell, Jeon, \& Barch, 2004; Vansteenkiste, Simons, Lens, Sheldon, \& Deci, 2004).
Teoricamente, haveria uma integração harmônica entre as demandas externas e o self, que traria como resultado maior autonomia e bem-estar naquelas situações em que os estudantes se percebessem capazes de se expressar e de superar os desafios da sala de aula. Nesse caso, o efeito da interação entre os recursos internos e as influências socioculturais seria de síntese. Em contraposição, quanto mais a desmotivação e o controle operassem, interferindo de modo negativo na iniciativa e no engajamento, o efeito de síntese ou de harmonia seria prejudicado, o que resultaria em baixos resultados de desempenho e de aprendizagem. A motivação intrínseca, nesse caso, seria a condição mais autodeterminada para a realização de uma atividade, ou seja, pelo interesse ou satisfação a ela inerentes. A motivação extrínseca poderia ser diferenciada em tipos variados de autodeterminação do comportamento, caso o processo de internalização das demandas e valores externos seja bem-sucedido (Reeve, Deci, \& Ryan, 2004).

O conceito de internalização refere-se ao processo proativo pelo qual as regulações externas, que são as práticas e as prescrições culturais, são transformadas em autorregulações, ou seja, tornam-se valores, crenças e compreensões pessoais. A introjeção é a forma mais elementar e imperfeita de internalização, se comparada com as formas progressivamente mais acabadas, que são a identificação, a integração e a motivação intrínseca. Entretanto, não se deve supor que uma pessoa percorra necessariamente a sequência de pontos do continuum de autodeterminação no que se refere às demandas externas (motivação extrínseca por regulação externa, introjetada, identificada e integrada) para ter plenamente regulado um comportamento em particular. Os tipos de regulação representam referenciais para análise do nível de internalização alcançado em uma dada situação (Bzuneck \& Guimarães, 2010; Ryan \& Deci, 2000a, 2000b; Vansteenkiste, Lens, \& Deci, 2006). 
De acordo com Ryan e Weinstein (2009), pode-se considerar que, pelo menos em parte, as atividades escolares não são interessantes ou agradáveis de se realizar, isto é, não mobilizam os processos intrapessoais para o envolvimento dos estudantes. Reconhecendo a complexidade e a multiplicidade de fatores envolvidos na falta de interesse, podemos destacar, de acordo com Brophy (1999), a obrigatoriedade e a descontextualização dos conteúdos, a falta de conhecimentos prévios e a avaliação classificatória com a divulgação pública dos resultados, entre outros. Desse modo, a internalização da motivação extrínseca, resultado de processos interpessoais, é essencial para a autoiniciativa e a manutenção da vontade de estudar. Nessa perspectiva, a qualidade motivacional dos estudantes seria parcialmente influenciada pelo estilo de interação proporcionada pelo professor, que controla ou promove a autonomia. Apesar de não poder se motivar no lugar dos seus alunos, podem ser oferecidas oportunidades para que estes descubram quais são seus interesses, o que tem valor e o que é significativo naquele contexto (Bzuneck, 2010; Reeve, 2009; Reeve, Deci, Ryan, 2004).

\section{Estilo motivacional de professores}

O estilo motivacional refere-se aos sentimentos e aos comportamentos que o professor demonstra em suas interações com os alunos. É considerado uma característica decorrente da personalidade, do aprendizado e de influências do contexto social, como, por exemplo, o número de alunos por sala, a fase de desenvolvimento dos alunos e as interações entre o professor e a equipe pedagógica ou a direção da escola, entre outros (Bzuneck \& Guimarães, 2007; Deci et al., 1981; Reeve, 2009).

Os professores não deliberam, pelo menos de modo permanente, a respeito da adoção de um estilo motivacional controlador, mas, muitas vezes, consideram a motivação e o engajamento dos estudantes somente de acordo com sua própria perspectiva. Assim, acabam por interferir nos sentimentos, pensamentos e modos de agir dos alunos, além de pressioná-los para pensarem, agirem e sentirem de alguma forma particular. Ressalta-se que o fato de o professor sugerir aos alunos algumas estratégias de aprendizagem, recomendar que prestem atenção às instruções ou controlar algumas emoções negativas não torna o ambiente ou a interação controladora. O controle é uma característica do professor em sala de aula quando a perspectiva do aluno é desconsiderada ou quando ele é impedido de manifestá-la.

O estilo motivacional do professor é revelado, ainda de acordo com Reeve, de modo direto e indireto. O professor controla diretamente seus alunos quando cria motivos externos para a ação, como a imposição de prazos, os comandos verbais ou os incentivos. Dessa forma, proporciona a percepção de locus externo para a ação ou, em outras palavras, os alunos percebem que as razões para agir estão alocadas fora da atividade. O controle indireto, por sua vez, pode ser alcançado quando, de modo manifesto ou dissimulado, o professor fomenta no aluno compulsões internas para a ação, mediante sentimentos de culpa, vergonha e ansiedade, ou seja, as razões introjetadas que justificam a ação estão voltadas para a proteção do self, pois, agir em conformidade com o que é socialmente esperado ou valorizado evita sentimentos desagradáveis. Um exemplo desse comportamento é o estudante que permanece em sala de aula para evitar ser avaliado como relapso pelo professor.

Por outro lado, o professor pode adotar um estilo promotor de autonomia de seus alunos na medida em que tem sucesso na obtenção das seguintes metas: nutrir os recursos motivacionais internos dos estudantes mediante a satisfação das necessidades psicológicas básicas de 
autonomia, competência e pertencimento, oferecer razões significativas para o envolvimento em atividades aparentemente pouco interessantes ou satisfatórias, fazer uso de linguagem informativa, não controladora, respeitar o ritmo de aprendizagem do aluno e reconhecer e aceitar a manifestação de emoções negativas no ambiente de sala de aula. Reeve descreve algumas investigações cujos resultados evidenciam os benefícios para a aprendizagem e o desenvolvimento dos estudantes quando são estabelecidas interações promotoras de autonomia.

Bzuneck e Guimarães (2007) tiveram por objetivo levantar as propriedades psicométricas de uma adaptação do instrumento de avaliação do estilo motivacional de professores, problemas nas escolas, de Deci, Schwartz, Sheinman e Ryan (1981). Além de comprovarem a validade da escala, os autores puderam também identificar a preferência de uma amostra de professores brasileiros $(N=1296)$ pelo uso de estratégias motivacionais de promoção de autonomia ou de controle. Os resultados mostraram que foi acentuada a preferência dos professores por estratégias promotoras de autonomia $(M=$ $6,01 \mathrm{dp}=0,73)$, em uma proporção mais de duas vezes maior que a opção por estratégias de controle, cuja média foi de 2,72 (dp=1,01).

Esse dado soa como revelação de uma tendência educacionalmente muito positiva daqueles professores, com possíveis reflexos na sua atuação em sala de aula e em toda a realidade educacional brasileira, isto é, ao menos em princípio, o dado significa que aqueles professores revelam uma propensão a promover motivação autônoma, por meio do apoio à autonomia ou à autodeterminação. Reeve (2002) argumenta que deter o conceito teórico do que seja dar apoio à autonomia afeta a prática dos professores por lhes fornecer uma orientação prescritiva sobre o que deve ser feito, caso eles estejam interessados em desenvolver nos alunos tal senso de autonomia.
Entretanto, uma importante questão que os dados de Bzuneck e Guimarães (2007) levantam diz respeito aos comportamentos de tais professores em classe, ou seja, pode-se concluir que sua predisposição ou orientação cognitiva favorável à autonomia dos alunos, como foi revelada nas respostas verbais ao teste, será aplicada e manifestar-se-á regularmente em comportamentos promotores de autonomia? Em outras palavras, a prática em sala de aula refletirá de modo habitual aquela predisposição interna?

Em sua pesquisa, Bzuneck e Guimarães (2007) não focalizaram esse pormenor, ou seja, o questionário de autorrelato limitou-se a investigar julgamentos sobre as oito situações hipotéticas ali apresentadas no formato de vinhetas. Entretanto, em princípio, poder-se-ia argumentar que, de um lado, está a predisposição para evitar o uso de controladores, e, de outro, as reações comportamentais do professor ao se defrontar com os problemas reais de um determinado aluno ou da classe inteira, que constituem a complexidade do cotidiano escolar. Acresce que tais situações reais têm componentes que nenhuma vinheta conseguiria descrever adequadamente, daí a suposição de um certo descompasso entre o julgamento ou discurso cognitivo frente a uma situação hipotética e o que a pessoa realmente faria em situações reais.

Constatar esse fato deu impulso à elaboração do presente trabalho, que teve como objetivo investigar, por meio da observação em sala de aula, se as interações entre os professores e seus alunos se relacionam com os estilos motivacionais avaliados pelo problemas nas escolas e, ainda, que tipo de interações, controladoras ou promotoras de autonomia, os professores estabelecem com os alunos.

\section{Participantes}

Trinta e nove professores do gênero feminino, que atuavam na rede pública de ensino 
fundamental do norte do Paraná, com idades variando entre 29 a 50 anos, participaram da pesquisa. O resultado da análise do desempenho dos professores na avaliação do estilo motivacional não permitiu caracterizálos como prevalentemente promotores de autonomia ou controladores, considerando o sistema de pontuação sugerido pelos autores da escala original. No entanto, pode-se destacar que alguns professores concordaram com afirmativas relacionadas ao estilo alto promotor de autonomia, cinco a seis vezes em oito possíveis (6 participantes), e que outros não assinalaram afirmativas promotoras de de autonomia (2 participantes).

Em seguida, verificou-se, com cada um desses professores, a possibilidade de observação em sua sala de aula. Do grupo que concordou em ser observado, foi escolhido o professor com pontuação mais alta e o professor com mais baixa pontuação na avaliação do estilo motivacional, para que participassem do estudo.

Os dois professores eram do gênero feminino, estando P1 na faixa etária entre 31 a 50 anos (39 anos), com 4 a 10 anos (7 anos) de experiência e lecionando em uma turma com 17 alunos da 3 a série do ensino fundamental e P2, na faixa etária entre 31 a 50 anos (46 anos), tinha 20 anos de experiência e lecionava na $1 \underline{a}$ série do ensino fundamental, em uma turma com 23 alunos.

\section{Instrumentos}

\section{Questionário Problemas na Escola}

A avaliação do estilo motivacional de professores foi realizada mediante o instrumento problemas na escola, elaborado por Deci et al. (1981), adaptado e validado no Brasil por Bzuneck e Guimarães (2007). O instrumento contém oito histórias que envolvem problemas cotidianos na interação entre crianças e adultos, e, para cada história, o professor participante deve assinalar o seu grau de concordância (em Escala Likert de sete pontos) em relação a quatro soluções para o problema apresentado, cada uma correspondendo a um estilo motivacional. Assim, 32 itens avaliam o estilo motivacional do professor, sendo eles: alto promotor de autonomia (AA), em que o papel do professor é incentivar o aluno a buscar soluções autônomas para os seus problemas; moderado promotor de autonomia (MA), no qual o professor encoraja o aluno a ter empatia pela sua forma de compreender, diagnosticar e resolver um problema; moderado controlador (MC), em que o professor percebe uma solução e encoraja o aluno a aplicá-la recorrendo ao senso interno de obrigação do aluno ou para o que os outros julgam correto; alto controlador (AC), no qual o professor identifica uma solução e, através de estímulos extrínsecos, direciona os alunos a alcançarem o resultado desejado por ele. É nesse último estilo que a regulação externa tem seu ápice, visto que o professor entende que o controle da sala só é possível mediante o uso de recompensas e de pressões externas, criando um clima interpessoal de absoluto controle.

Para a pontuação do estilo motivacional dos participantes, foi adotada uma ponderação dos escores médios em cada uma das quatro subescalas. Dessa forma, o escore final na subescala de estilo alto controlador resulta do escore inicial pela marcação nos itens, multiplicado por -2, a subescala do estilo moderado controlador receberá o peso -1 , a subescala de estilo moderado promotor de autonomia, +1 , e, por fim, o alto promotor de autonomia, 2(AA)+MA-MC-2(AC). Essa fórmula calcula o desempenho do participante por questão. Tome-se como exemplo o item do questionário abaixo:

Luís é um aluno médio, com desempenho no nível de sua classe. Entretanto, nas duas últimas semanas, ele parece desatento, apático, e não tem participado do grupo de 
leitura. O trabalho que faz é bem feito, mas ele não tem completado as tarefas. Uma conversa pelo telefone com a mãe dele não trouxe informações úteis. A coisa mais apropriada para a professora de Luís fazer é:

(a) acentuar para ele a importância de terminar suas tarefas porque ele precisa aprender esse conteúdo para o seu próprio bem;

(b) informá-lo de que ele não precisa terminar todo o trabalho e verificar se ela pode ajudá-lo a descobrir a causa de sua desatenção;

(c) fazê-lo ficar depois da aula até o dia em que as tarefas sejam completadas;

(d) levá-lo a se comparar com os colegas no que diz respeito à realização das tarefas e encorajá-lo a alcançá-los (vide Anexo A, para o questionário completo).

Caso o participante assinale 7 na afirmativa a, 2 na $b, 1$ na c e 3 na d, o cálculo seria:

2. (2) + 3- 7- 2.(1), resultando em -2 . Dessa forma, considerando que o desempenho poderia variar de -18 a +18 , ou seja, com intervalo de 36 pontos, podemos classificar os estilos em quatro intervalos: de -18 a -9 (AC), de -8 a 0 (MC), de 1 a 9 ( MA) e de 10 a 18 (AA). No caso hipotético, o professor teria um desempenho moderado controlador.

\section{Roteiro de observação}

Totalizando 14 sessões de observação exploratória, com duração de dez minutos cada uma, realizadas por duas pesquisadoras, as informações foram divididas em duas categorias, que serviram para a elaboração de um roteiro para coleta de informações acerca do relacionamento entre o professor e seus alunos em sala de aula. A primeira categoria referiu-se aos processos de organização do professor quanto ao tempo, à atividade e aos comportamentos do aluno (ex: se o professor concede tempo extra solicitado, atendendo ao pedido do aluno ou para possibilitar a conclusão do trabalho, ou se oferece escolhas: apresenta alternativas de escolha sobre a organização das tarefas e estratégias de realização). A segunda fez referência ao feedback que o professor dá aos alunos (ex: se o professor responde prontamente as perguntas e pergunta sobre a existência de dúvidas para todos os estudantes, ou ainda, se expressa insatisfação com a forma como a atividade está sendo executada).

O roteiro serviu de instrumento para a realização de mais sete sessões de observação, de aproximadamente 10 minutos cada, cujo objetivo foi registrar a frequência em que as interações ocorriam.

\section{Procedimentos}

Inicialmente foi aplicado o Questionário Problemas na Escola para um grupo de 39 participantes com o objetivo de avaliar seus estilos motivacionais. Foi pedido que todos os professores se identificassem ao responder o questionário para que um contato posterior fosse possível. Os procedimentos éticos foram respeitados, e os participantes, após serem informados a respeito dos objetivos e das etapas da pesquisa, assinaram o Termo de Consentimento Livre e Esclarecido, de acordo com a indicação do Comitê de Ética da Instituição, portanto, respaldados pela Resolução no 196/96, do Conselho Nacional de Saúde e seus complementares.

Após a seleção de dois professores, um avaliado como controlador e um como promotor de autonomia, de acordo com o desempenho na avaliação do estilo motivacional, realizouse, já no campo de estudo, uma observação exploratória para identificar as diversas interações entre o professor e seus alunos. As observações se deram em sete sessões de dez minutos de duração, nas quais duas observadoras realizaram registro cursivo das 
interações do professor com os alunos. Os índices de concordância entre os registros de observação realizados variaram de 64 a $100 \%$. Por interação, compreenderam-se aqui gestos, palavras, silêncios, expressões faciais e corporais do professor em direção aos alunos. Cada professor foi observado separadamente, em dias e horários diferentes, ressaltando-se que as observadoras não conheciam, naquela etapa, o resultado obtido pelos professores na avaliação do estilo motivacional. Tomou-se esse cuidado para evitar a criação de expectativas em relação aos estilos de interação. A partir dos resultados das primeiras observações, foram definidas as categorias de interações controladoras e promotoras de autonomia para orientar a observação sistemática.

\section{Resultados e discussão}

Tendo como base a caracterização indicada pela literatura (Newby, 1991; Reeve, 1998; Reeve, Bolt, \& Cai, 1999; Reeve \& Jang; 2006; Reeve et al., 2004) do que seria promover autonomia ou controle em sala de aula, formaram-se dois grupos-categorias: a primeira, relativa aos processos de organização do tempo, da atividade e dos comportamentos do aluno; a segunda, concernente ao feedback oferecido aos alunos.

A categoria focalizando o tempo compreendeu ouvir com atenção, ser flexível, reconhecer as perspectivas e o tempo de cada aluno. Com base nos resultados, buscou-se captar, nas ações do professor, sua sensibilidade às queixas dos alunos no que dizia respeito à falta ou ao excesso de tempo destinado à realização de uma determinada atividade. Foram assim definidas as interações: apressa ou antecipa a execução da tarefa, solicita a conclusão rápida do trabalho, reclama da demora, permite que o estudante termine a atividade, no caso de o tempo extrapolar ao previamente combinado, cobra prazos, faz ameaças de punição se não acabarem no tempo combinado.
Algumas frases e comportamentos registrados exemplificam o grupo de ações nessa categoria: "Faltam só cinco minutos; quem terminar, terminou, quem não terminar fica no recreio pra acabar de fazer"; "Vocês só têm até meio-dia, se não acabarem, vão ficar sem nota", ou com atitudes e gestos como ficar batendo o pé ao lado da carteira do aluno que está atrasado, ficar olhando para o relógio e bater a mão no relógio dizendo que o tempo está acabando.

Para a categoria focalizando a atividade, previa-se identificar as ações do professor em relação à maneira de conduzir as tarefas propostas, e, para tanto, com base no registro das observações, foram agrupadas as ações: explicita condições gerais, orienta e instrui acerca da realização da atividade, indica os materiais, comportamentos e /ou organização necessários para a execução da atividade, de costas para os alunos, escreve o conteúdo no quadro enquanto lhes dá instruções, escreve no quadro sem verbalizar, manuseia o material da atividade, distribui materiais necessários para a realização da atividade, ou auxilia o aluno no seu manuseio, esclarece aos alunos os motivos ou metas para a realização da atividade, dá respostas sem que os alunos tenham tempo ou se esforcem para pensar em uma possível solução e relaciona o conteúdo com o dia a dia dos alunos.

Na categoria focalizando o comportamento, foram agrupadas as interações: estimula/cria condições para o envolvimento do aluno na tarefa, enfatiza a boa execução de tarefas, por meio de enunciações verbais positivas, responde prontamente à solicitação do aluno, faz perguntas e estimula a emissão de respostas, planeja e implementa tarefas curtas ou voltadas para apresentações de habilidades, estimula positivamente a participação dos alunos, faz contato visual, varia o ritmo e o volume da vOz ao falar, faz pausa e silêncios para causar ênfase, demonstra compreensão e empatia com a forma de pensar e de agir e com os erros e os acertos dos alunos, permanece parada 
ou caminha observando/supervisionando a execução da atividade e altera o tom de voz e a expressão facial ao referir-se a um aluno. Tais ações, agrupadas nessa categoria, estão relacionadas às proposições de levar os alunos a guiarem seus comportamentos utilizando seus recursos internos, de utilizar linguagem não controladora, de reconhecer e aceitar expressões de emoções negativas e positivas dos estudantes, de ouvir cuidadosamente e de dar atenção às suas perspectivas, ou seja, são interações alinhadas com a promoção de um ambiente social promotor de autonomia. Ainda com base nos registros da observação exploratória, quando as professoras focalizaram o comportamento do aluno com vista a controlá-lo, foram agrupadas ações como: utilizar recompensas externas, repreensões ou ameaças para obter a atenção ou o envolvimento na tarefa, controlar ou supervisionar a emissão de comportamentos durante a atividade, ignorar comportamento incompatível com a realização da atividade, permanecer parada ou caminhar observando/ supervisionando a execução da atividade e alterar o tom de Voz e a expressão facial ao referir-se a um aluno. Tais ações são compatíveis com a caracterização do estilo motivacional alto controlador, ou de controle direto (Reeve et al., 1999; Reeve, 2009), no qual o professor estabelece formas específicas de comportamentos, define o que os estudantes devem fazer, oferece estímulos extrínsecos (recompensas, ameaças e punições), utiliza a linguagem controladora para moldar os alunos, comunica-se utilizando diretivas e comandos e utiliza verbos no imperativo. Nesse estilo, o foco do professor é manter os alunos conformados ao seu plano de trabalho, ao que ele considera como comportamento ou atitude desejável para aquele momento da aula. Exemplos extraídos das observações: “J., senta direito, põe a mão na carteira, põe o pé pra dentro da carteira"; "Já não mandei você ficar quieto? Você só sabe atrapalhar"; "Pega no lápis direito, desse jeito você não aprende a escrever".
Finalmente, a segunda categoria de feedback agrupou as interações nas quais o professor informava ao aluno os resultados das suas avaliações e da realização das atividades, além de comunicar o que estava pensando e o que sentia em relação ao processo de aprendizado do aluno. Foram considerados feedbacks promotores de autonomia, extraídos dos registros das observações exploratórias, as seguintes ações: ajuda o aluno a ver seu próprio progresso, expressa satisfação ou insatisfação com a forma de execução da atividade (de modo informativo), salienta ao estudante o quanto melhorou em relação ao seu próprio resultado, responde prontamente às perguntas e incita os alunos a apresentarem suas dúvidas para os colegas, repete o conteúdo verbalizado pelo estudante (apoiando), interfere minimamente na comunicação oral do aluno, atende o aluno individualmente na mesa da professora ou passa pelas carteiras atendendo-os separadamente, mostra, dá exemplos ao estudante de como utilizar estratégias de aprendizagem adequadas, sorri, faz gestos de positivo, acena afirmativamente com a cabeça e estabelece contato físico, demonstrando afeto.

As ações observadas e agrupadas na categoria feedback, com potencial para a promoção de autonomia, correspondem ao proposto na caracterização do estilo motivacional alto promotor de autonomia: identificar e nutrir as necessidades básicas dos estudantes, considerar seus interesses e preferências, criar oportunidades para que os recursos internos dos alunos sirvam de orientação para seus próprios comportamentos, utilizar linguagem não controladora, contextualizar, comunicar o valor e a relevância das atividades, ser flexível, reconhecer e aceitar as expressões negativas dos estudantes e suas perspectivas, ouvir cuidadosamente, criar oportunidades para que os estudantes trabalhem de seu modo para a resolução de problemas e encorajar os alunos a persistirem e a se esforçarem nas tarefas de aprendizagem. 
As interações mais frequentes relativas a essa categoria foram registradas em situações nas quais o professor valorizou, verbalmente ou com gestos, o que o aluno conseguiu fazer. No entanto, tais comunicações não foram feitas com o intuito de levar o aluno a se perceber como melhor do que os outros, mas no sentido de fazê-lo reconhecer sua evolução. Exemplos disso são as afirmativas "A., se você olhar para o que está escrito na primeira página do seu caderno e para a que você está escrevendo agora, verá como sua letra melhorou"; "C., venha aqui no quadro e mostre como você solucionou o exercício 2" (aluna resolve); "Muito bem, algum aluno fez este exercício de uma forma diferente?" Em um episódio observado, um aluno teve dificuldade de perceber um erro na atividade realizada, então a professora pediu que ele consultasse os materiais disponíveis na sala de aula, permitiu que ele se levantasse e até mesmo que consultasse alguns colegas. Algum tempo depois, o aluno chamou a professora e mostrou o exercício refeito. Em seu discurso, a professora salientou o quanto é importante que se façam perguntas e que sejam utilizados todos os recursos possíveis para que a dúvida seja desfeita.

As interações controladoras observadas, agrupadas na categoria feedback, foram: rejeita resposta do estudante, expressa satisfação ou insatisfação com a forma de execução da atividade, respectivamente, quando se aproxima ou se distancia do previsto, compara o ritmo e/ou resultado da atividade entre os alunos, ignora pergunta do estudante, questiona a resposta do aluno repetindo-a em tom interrogativo, corrige a expressão verbal e escrita do estudante, expondo-o diante dos outros colegas, interage com gritos, ofensas, muda a expressão facial (exemplo: franze a testa) e toca o aluno de modo agressivo (segura-o pelos ombros e sacode-o).

A literatura sugere (Reeve et al., 2004) que interações controladoras, como as descritas anteriormente, interferem na autodeterminação dos estudantes, pois tendem a convencê-los a aderir aos valores, crenças e regras do professor, as quais, no conjunto, definem o que devem fazer. Nesse sentido, em tais interações, o professor ignora os recursos internos dos alunos, oferece estímulos extrínsecos - como elogios e prêmios quando o resultado se aproxima do estipulado -, utiliza linguagem controladora para moldar os alunos, dá a resposta certa sem que os alunos tenham se esforçado para pensar, compara o desempenho dos alunos, comunica-se utilizando diretivas e comandos, utiliza verbos no imperativo e faz perguntas de maneira controladora (Reeve et al., 2004).

Exemplos desse tipo de interação foram frequentes nas amostras de interações observadas: "Veja como L. está de parabéns, ela fez exatamente como mandei"; "J., será que você nunca vai aprender quanto é dois mais dois?"; "Eu já estou cansada de explicar; M., fica quieto e vira pra frente!" Em um episódio observado, a professora vai até o quadro e escreve, ao mesmo tempo em que verbaliza: "É com s, a cobrinha!" Enquanto a aluna tentava refazer o exercício, voltou até a sua carteira, e, percebendo que ela não conseguia fazer, apagou do caderno o que a estudante havia escrito e escreveu ela própria a letra para que a atividade fosse concluída.

\section{Frequências das interações}

Após a construção do protocolo de observação, foram realizadas mais sete sessões de observação na sala de aula de P1 e P2, agora com o intuito de verificar com que frequência ocorriam as categorias de interação. Os resultados de observação, apresentados na Tabela 1, indicam que ambas as professoras utilizaram mais estratégias controladoras do que promotoras de autonomia, porém, evidencia-se que P2, na amostra de interações observadas, apresentou um equilíbrio entre controle e promoção de autonomia. 
Tabela 1. Comparação das interações de P1 e P2 de acordo com o registro das duas observadoras

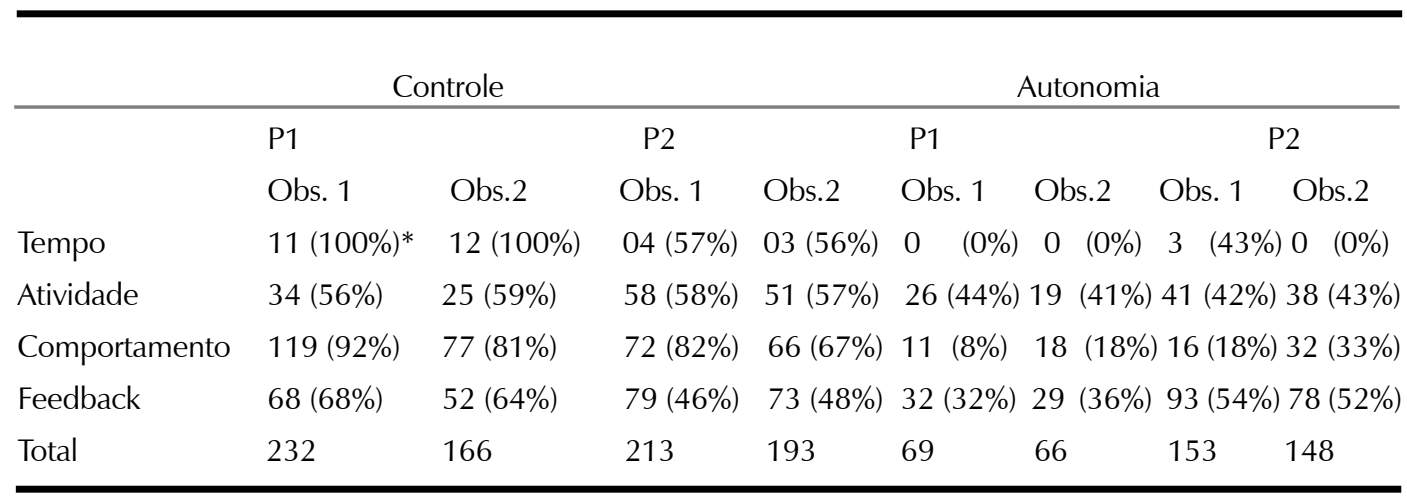

Nota: As porcentagens apresentadas são referentes ao total de interações registradas em cada categoria por observador.

O critério utilizado para julgar se a ocorrência de interação se caracterizava como controladora ou promotora de autonomia se pautou na proposta feita por Reeve et al. (2004) a respeito da ação do professor em sala de aula. As pesquisadoras, munidas dos protocolos, assinalavam na folha cada tipo de interação observado durante as sessões. Vale ressaltar que tal protocolo já continha os tipos de interações previstos para cada um dos estilos analisados. Dessa forma, os professores controladores caracterizam-se por criarem um clima de baixa liberdade em sala de aula, por interferirem na autodeterminação dos estudantes, pois tendem a convencê-los a aderir aos seus valores, crenças e regras que, no conjunto, definem o que os estudantes devem fazer, por oferecerem estímulos extrínsecos e utilizarem a linguagem controladora para moldar os alunos como querem. São ainda características desse estilo: mostrar aos alunos a resposta certa, comunicar verbalmente as respostas certas sem que os alunos tenham se esforçado para pensar, comunicar-se utilizando diretivas e comandos, utilizar-se de verbos no imperativo e fazer perguntas de maneira controladora (Reeve, 2009; Reeve et al., 2004).

Em contrapartida, professores que têm estilo motivacional mais próximo da promoção de autonomia buscam identificar e nutrir as necessidades básicas dos estudantes, seus interesses e preferências e criam oportunidades para que os recursos internos dos alunos guiem seus próprios comportamentos. Na sala de aula desses professores, observa-se um clima de liberdade de escolha, de disponibilidade, de atenção e de iniciativa. Eles nutrem os recursos internos de seus alunos, utilizam uma linguagem não controladora, comunicam o valor das atividades, por exemplo, para o conhecimento de vida, reconhecem e aceitam as expressões negativas dos estudantes, ouvem cuidadosamente, permitem que os alunos trabalhem a seu modo para a resolução de problemas, abrem espaço para os estudantes falarem, disponibilizam diferentes materiais para os alunos manipularem, encorajam-nos a persistir e a se esforçar e a reconhecer suas perspectivas (Reeve, 2009; Reeve et al., 2004).

\section{Considerações finais}

O estilo motivacional do professor materializa-se em sala de aula por meio de suas interações com os alunos. O ambiente evidencia o controle quando as perspectivas do aluno são preteridas para dar lugar somente aos interesses, valores e crenças do professor. Nesse caso, os estudantes realizam as atividades escolares por pressão externa, por um sentimento de obrigação induzido pelo professor ou no sentido de evitar emoções negativas, como culpa ou vergonha. Em contraposição, no contexto 
de autonomia, os recursos motivacionais internos do estudante (competência, autonomia e pertencimento) são considerados e sustentados. O envolvimento aqui é resultado da percepção de um lócus interno de causalidade, de vontade e de escolha. A literatura registra os benefícios para o desenvolvimento, a aprendizagem e o bemestar psicológico dos estudantes quando se adota um estilo motivacional promotor de autonomia. Os dados apresentados, tanto na pesquisa realizada por Bzuneck e Guimarães (2007) como os coletados para a amostra inicial deste estudo, corroboram a ideia de que uma sala de aula organizada de modo a promover a autonomia dos estudantes seja de fácil aceitação por parte dos educadores. Em contrapartida, parece menos plausível assumir publicamente que se é favorável ao controle dos comportamentos, pensamentos e sentimentos dos estudantes na escola. Essa parece ser uma justificativa possível para os resultados obtidos pelos professores na avaliação do estilo motivacional, em ambos os trabalhos supracitados.

As observações realizadas em sala de aula de dois professores que adotaram estilos motivacionais diferenciados permitiram avançar no conhecimento da área. De modo preferencial, os estudos brasileiros e estrangeiros na área da motivação têm empregado instrumentos de autorrelato. Apesar da grande contribuição desses estudos exploratórios, segundo Bzuneck e Guimarães (2010), há uma distância entre uma crença ou predisposição favorável à promoção de autonomia e as ações do professor em um ambiente dinâmico, complexo, multideterminado e que exige, constantemente, rápidas tomadas de decisão. As duas professoras participantes da pesquisa adotaram interações controladoras em sala de aula, e, para Reeve (2009), existem algumas razões que justificam a preferência dos professores pelo controle. Algumas são influências externamente impostas, como, por exemplo, as políticas educacionais, as cobranças da direção da escola, dos pais e as expectativas da sociedade em relação à educação ou as normas culturais. Não seria surpresa que a pressão para produzir melhores resultados com os alunos envolvesse comportamentos mais controladores por parte dos professores. Pressões externas frequentemente exigem que os professores trabalhem com o objetivo de levar os alunos a melhorarem os resultados de desempenho, a cumprirem os conteúdos específicos em prazos pré-determinados ou a alcançarem padrões mais altos para os seus estudantes (Ryan \& LaGuardia, 1999).

Nesse sentido, pelo fato de se perceber controlado externamente (locus externo de causalidade), o professor também seria instigado a controlar seus alunos para que caminhassem nas direções prescritas. Outra natureza de influências está no próprio ambiente de sala de aula, como a reações dos alunos às ações do professor, por exemplo, demonstrando atenção (ou falta dela) ao que o professor fala e cumprindo as tarefas, entre outras. Tais influências interagem com as disposições de personalidade, crenças e valores do próprio professor, resultando em formas diferenciadas de interação, neste caso, controladoras ou promotoras de autonomia. Além disso, pode-se analisar como fonte de influência a própria formação de professores, realizada também em um contexto de controle. Queiroz \& Barbosa-Lima (2007), analisando a formação de licenciatura em Física, argumentam que os alunos saem com uma visão estereotipada do que é ser professor, quase que exclusivamente apoiada na sua própria trajetória de escolarização. Esse quadro, acreditamos, pode ser generalizado para a formação em outras licenciaturas.

Descobrir e compreender as razões subjacentes às interações entre os professores e seus alunos ainda exige muita investigação. As professoras participantes desta pesquisa optaram por utilizar estratégias de interações baseadas no 
controle. Esse dado só se tornou evidente ou verificável ao se observar em sala de aula como se dava essa interação, pois, se analisássemos os dados exclusivamente por meio do instrumento de autorrelato, não seria possível identificar as diferenças qualitativas das interações empreendidas pelas duas professoras investigadas. Nesse aspecto, o protocolo construído no presente trabalho, além de conseguir captar, por meio das observações exploratórias, o que se passava nas salas de aula de P1 e P2, mostrou-se bem fiel ao que conceitualmente era previsto para dimensões de uso do controle e de promoção de autonomia.

Como limitações do estudo, podemos indicar o fato de terem sido investigadas apenas duas professoras, além do número reduzido de interações observadas. Sugere-se que, em estudos posteriores, os pesquisadores permaneçam mais tempo dentro da sala de aula para que, assim, se tornem mais familiares para os alunos e professoras e possam compreender melhor como ocorre a dinâmica da sala de aula. Apesar das limitações, foi possível, no presente estudo, contextualizar para o ambiente de duas salas de aulas brasileiras alguns dos pressupostos de uma abordagem teórica recente, pouco pesquisada em nossa realidade, e, dessa forma, pôde-se contribuir para a área com um protocolo de categorias de interação para uso em futuras pesquisas.

Amélia Carolina Terra Alves Machado

Mestrado em Educação pela Universidade Estadual de Londrina, Docente do Instituto Superior de Educação do Paraná, Paraná - PR - Brasil.

E-mail: melterramar@hotmail.com

\section{Sueli Édi Rufini}

Doutorado em Educação pela Universidade Estadual de Campinas, Professor Associado A da Universidade Estadual de Londrina, Paraná - PR - Brasil.

E-mail: sueli_rufini@hotmail.com

\section{Aline Guilherme Maciel}

Especialização em Psicopedagogia pelo Instituto de Estudos Avançados e Pós-Graduação, Mestrado em Educaçao na Universidade Estadual de Londrina, Paraná - PR - Brasil.

E-mail: alinegmaciel@yahoo.com.br

\section{José Aloyseo Bzuneck}

Doutorado em Psicologia Escolar e do Desenvolvimento Humano pela Universidade de São Paulo, Professor titular da Universidade Estadual de Londrina,Paraná - PR - Brasil.

E-mail: bzuneck@sercomtel.com.br

Endereço para envio de correspondência:

Rua Espírito Santo, 1257, Paraná - PR - Brasil. CEP: 86020-420

Recebido 24/5/2011, 1a Reformulação 16/9/2011, Aprovado 15/10/2011. 


\section{Referências}

Assor, A., Kaplan, H., \& Roth, G. (2002). Choice is good, but relevance is excellent: Autonomy-enhancing and suppressing teacher behaviors predicting students' engagement in schoolwork. British Journal of Educational Psychology, 72, 261-278.

Black, A. E., \& Deci, E. L. (2000). The effects of student selfregulation and instructor autonomy support on learning in a college-level natural science course: A self-determination theory perspective. Science Education, 84, 740 -756.

Boruchovitch, E. (2008). A motivação para aprender de estudantes em cursos de formação de professores. Educação, 31(64), 30-38.

Brophy, J. (1999). Motivating students to learn. Boston: McGraw Hill.

Bzuneck, J. A. (2009). A motivação do aluno: aspectos introdutórios. In E. Boruchovitch \& J. A. Bzuneck (Orgs.), A motivação do aluno: contribuições da psicologia contemporânea (pp. 09-36). Petrópolis, RJ: Editora Vozes.

Bzuneck, J. A. (2010). Como motivar os alunos: sugestões práticas. In E. Boruchovitch, J. A. Bzuneck \& S. E. R. Guimarães (Orgs.), Motivação para aprender: aplicações no contexto educativo (pp.13-42). Petrópolis RJ: Editora Vozes.

Bzuneck, J. A., \& Guimarães, S. E. R. (2007). Estilos de professores na promoção da motivação intrínseca: reformulação e validação de instrumento. Psicologia: Teoria e Pesquisa, 23(4), 415-421.

Bzuneck, J. A., \& Guimarães, S. É. R. (2010). A promoção da autonomia como estratégia motivacional na escola: uma análise teórica e empírica. In E. Boruchovitch, J. A. Bzuneck \& S. E. R. Guimarães (Orgs.), Motivação para aprender: aplicações no contexto educativo (pp. 43-70). Petrópolis RJ: Editora Vozes.

Deci, E. L., \& Ryan, R. M. (2000). The "what" and "why" of goal pursuits: Human needs and self-determination of behavior. Psychological Inquiry, 11(4), 227-268.

Deci, E. L., \& Ryan, R. M. (2004). Handbook of self-determination research. New York: The University Rochester Press.

Deci, E. L., Schwartz, A. J., Sheinman, L., \& Ryan, R. M. (1981). An instrument to assess adults'orientations toward control versus autonomy with children: Reflections on intrinsic motivation and perceived competence. Journal of Educational Psychology, 73(5), 642-650.

Mayer, J. D., Faber, M. A., \& Xu, X. (2007). Seventy-five years of motivation measures (1930-2005): A descriptive analysis. Motivation and Emotion, 31, 83-103.

Newby, T. J. (1991). Classroom motivation: Strategies of first-year teachers. Journal of Educational Psychology, 83(2), 195-200.

Queiroz, G. R. P. C., \& Barbosa-Lima, M. C. A. (2007). Conhecimento científico, seu ensino e aprendizagem: atualidade do construtivismo. Ciência \& Educação, 13, 273-291

Reeve, J. (1998). Autonomy support as an interpersonal motivating style: Is it teachable? Contemporary Educational Psychology, 23, 312-330.

Reeve, J. (2009). Why teachers adopt a controlling motivating style toward students and how they can become more autonomy supportive. Educational Psychologist, 44, 159-175

Reeve, J., Deci, E. L., \& Ryan, R. M. (2004). Self-determination theory: A dialectical framework for understanding socio-cultural influences on student motivation. In D. M. Mclnerney \& S. Van Etten (Eds.), Big theories revisited (pp. 31-60). Greenwich, CT: Information Age Press.

Reeve, J., Bolt, E., \& Cai, Y. (1999). Autonomy-supportive teachers: How they teach and motivate students. Journal of Educational Psychology, 91, 537-548.

Reeve, J., \& Jang, H. (2006). What teachers say and do to support students' autonomy during a learning activity. Journal of Educational Psychology, 98, 209-218.

Reeve, J., Jang, H., Carrell, D., Jeon, S., \& Barch, J. (2004). Enhancing students' engagement by increasing teachers' autonomy support. Motivation and Emotion, 28, 147-169.

Ryan, R. M., \& Deci, E. L. (2000a). Self-determination theory and the facilitation of intrinsic motivation, social development, and well-being. American Psychologist, 55, 68-78.

Ryan, R. M., \& Deci, E. L. (2000b). Intrinsic and extrinsic motivations: Classic definitions and new directions. Contemporary Educational Psychology, 25, 54-67.

Ryan, R. M., \& La Guardia, J. G. (1999). Achievement motivation within a pressured society: Intrinsic and extrinsic motivations to learn and the politics of school reform. In T. Urdan (Ed.), Advances in motivation and achievement (pp. 45-85). Greenwich, CT: JAI Press.

Ryan, R. M., \& Weinstein, N. (2009). Undermining quality teaching and learning. A self-determination theory perspective on highstakes testing. Theory and Research in Education, 7(2), 224-233.

Vansteenkiste, M., Simons, J., Lens, W., Sheldon, B., \& Deci, E. L. (2004). Motivationg learning, performance, and persistence: The synergistic role of intrinsic goals and autonomy support. Journal of Personality and Social Psychology, 87, 246-260.

Vansteenkiste, M., Lens, W., \& Deci, E. L. (2006). Intrinsic versus extrinsic goal contents in self-determination theory: Another look at the quality of academic motivation. Educational Psychologist, 41, 19-31.

Vansteenkiste, M., Smeets, S., Soenens, B., Lens, W., Matos, L., \& Deci, E. L. (2010). Autonomous and controlled regulation of performance-approach goals: Their relations to perfectionism and educational outcomes. Motivation and Emotion, 34(4), 333-353. 